\title{
Influence of weekday of surgery on operative complications. An analysis of 25.000 surgical procedures
}

Verena Müller*, Julia Strauchmann, Shadi Katou, Johann Pratschke and Corinna Langelotz

Department of Surgery, Charité-Universitätsmedizin Berlin, Campus Charité Mitte, Campus Virchow-Klinikum, Germany

\begin{abstract}
Background: Surgical procedures need to be performed safely on every day and night of the week. Operations on certain weekdays have recently been shown to be associated with increased risk. Patient concerns about their safety have to be taken seriously when surgery needs to be planned. Many patients also believe in negative effects of lunar constellations or Friday $13^{\text {th }}$. To establish a scientific basis for reassurement, we retrospectively analyzed surgical complications at a maximum care center, addressing these issues.
\end{abstract}

Methods: All surgical procedures and their complications from 2007-2014 were registered in the departmental morbidity registry. Complications resulting in the necessity for reoperations were analyzed and matched with the day of the week of the primary procedure, the day the complication occurred, the lunar cycle and Friday $13^{\text {th }}$.

Results: Over 25.000 procedures were performed, resulting in a total of 635 registered surgical complications requiring reoperations. Male and female patients were equally affected. Weekdays of the primary procedure did not show a difference in subsequent complications $(\mathrm{P}=0.227)$, but weekdays of revision surgery reached statistical difference of $\mathrm{P}=0.05$, with most reoperations taking place on Fridays. No correlation with any lunar constellation or Friday $13^{\text {th }}$ could be found, $\mathrm{P}=0.763$ and $\mathrm{P}=0.144$, respectively.

Discussion: This retrospective analysis could not show a heightened risk for reoperations due to the primary procedure being performed on certain weekdays. Patients can also be reassured that there is sufficient evidence that lunar cycles do not affect the occurrence of complications and reoperations, nor does Friday $13^{\text {th }}$.

Conclusion: This study proves surgical procedures to be being equally safe on any given weekday and any date of the month.

\section{Introduction}

Patient safety is the priority of surgeons, and the number one question of patients having to undergo any surgical procedure is, what risk it entails. This question should be answered as objectively as possible with respect to the department's quality data. But do we need to discuss the perfect day of the week for the surgery now? Recent analyses of possible effectors on mortality could show that the day of the week, on which the procedure was performed, had a significant influence. A study on mortality after nonemergent surgery found an increased rate for procedures performed on fridays versus monday to wednesday [1] another one showed higher mortality rates in patients with elective colorectal resections being performed on fridays versus monday to thursday [2]. Also there is a cultural belief in more than ten percent of the Western European population, that the moon affects health care and is assumed to have a negative effect on procedures, as the occurrence of Friday $13^{\text {th }}$ is supposed to be associated with worsened outcome [3]. Studies have been performed to analyze the effect of the lunar cycle on birth rates [4], emergency department presentations [5], cardiopulmonary resuscitations [6,7] and psychiatric disorders [8]. Surgery specific studies looked into the incidence of postoperative hemorrhage [9,10], intraoperative blood loss [11], morbidity and mortality after lung and breast cancer surgery $[12,13]$ and quality of radical cystectomy for bladder cancer [14] in relation to the lunar cycle. These studies could not show any effect of the moon. Therefore, the question ought to be addressed, whether surgical complications in general occur with different frequencies on certain weekdays and are possibly interrelated with lunar cycles. The current study analyzed the incidence of surgical complications requiring reoperations for more than 25.000 primary procedures with respect to weekday of the initial operation, lunar constellations and Friday $13^{\text {th }}$.

\section{Material and methods}

All surgical procedures from 2007-2014 at a maximum care center and their registered complications from the departmental morbidity registry were analyzed. They resulted in 635 cases with a surgical complication requiring a reoperation. Operations were performed by board certified surgeons or under their supervision, encompassing the departmental spectrum of general, visceral, thoracic and vascular surgery. Dates and weekday of the primary operation, occurrence of complications and date of the reoperation were analyzed and matched with the lunar phase, new moon, full moon, waxing and waning moon. Occurrences of Friday $13^{\text {th }}$ were also identified. Patient characteristics with respect to age, gender, weekday of the operation, type of primary procedure and type of complication were recorded. Age was calculated

Correspondence to: Verena Müller, Department of Surgery, Charité Universitätsmedizin Berlin, Campus Charité Mitte, Chariteplatz 1, 10117 Berlin, Germany, Tel: +49-30-450622165; Fax: +49-30-450622209; E-mail: verena.mueller@charite.de

Key words: Friday 13th, lunar cycle, operative complications, reoperation, weekday of procedure

Received: August 20, 2017; Accepted: September 06, 2017; Published: September 08, 2017 
from the date of birth for the operation date and age groups were formed for analysis. Incidences of complications requiring reoperations were calculated between groups. The Statistical Package for Social Sciences Software, SPSS, was used for statistical analysis. Pearson's Chi-square test was used for testing on equal distribution and confidence intervals on binomial distribution were generated according to ClopperPearson, Jeffreys and Likelihood calculations of probability. Fisher's Exact test was used to compare age among patients with complications. For numeric data, differences were analyzed by ANOVA and in case of significance confirmed by T-Test. P-values $<0.05$ were considered to be significant.

\section{Results}

Over 25.000 procedures were performed from 2007-2014, resulting in a total of 635 registered complications requiring reoperations. Most of the complications occurred within one week from the primary operation. Male and female patients were equally affected by complications, matching their proportions in the department's patient population, with $60 \%$ male $(\mathrm{N}=381)$ and $40 \%$ female patients $(\mathrm{N}=254)$. Mean age of the patients with complications was 61 years (median 63 years). Incidence of surgical complications was independent of age and gender. Main complications were wound infections $(\mathrm{N}=178)$, vascular occlusions $(\mathrm{N}=115)$, postoperative hemorrhage $(\mathrm{N}=89)$, anastomotic insufficiencies $(\mathrm{N}=75)$, hematomas $(\mathrm{N}=45)$ and pneumothoraces $(\mathrm{N}=26)$.

Within the eight-year period there were 418 Mondays, 418 Tuesdays, 418 Wednesdays, 417 Thursdays, 417 Fridays, 417 Saturdays and 417 Sundays. Full moon and new moon occurred on 99 days, waxing and waning moon on 1.361 and 1.363 days. Proportionately the majority of the procedures with subsequent surgical complications were performed during waxing or waning moon (47.6\% and $44.9 \%$ respectively) and $3.9 \%$ took place at full moon, $3.6 \%$ at new moon (Table 1). No increased incidence of operative complications could be shown for any lunar period, with $\mathrm{P}=0.763$. More than $50 \%$ of the complications occurred within 4 days of the primary procedure, more than $70 \%$ within 7 days postoperatively. Therefore, the lunar constellations changed only slightly, leading to similar results without statistically significant differences.

As for Friday $13^{\text {th }}$, altogether 417 Fridays occurred within the timespan, of which $3.4 \%$ happened to be on a $13^{\text {th }}$. Confidence intervals were calculated with three different methods (Clopper-Pearson, Jeffreys and Likelihood) with neither showing a heightened incidence of operative complications beyond the incidental distribution, $\mathrm{P}=$ 0.144 for the primary procedure and occurrence of the complications and reoperations happened to be on a Friday $13^{\text {th }}$ in only $1.6 \%$. Primary procedures took mostly place on weekdays with only $3 \%$ and $3.6 \%$ occurring on Saturdays and Sundays. No statistical significance in the incidence of operative complications could be observed for the weekdays $(\mathrm{P}=0.227)$, despite absolute numbers showing that most operations leading to subsequent complications were performed on Tuesdays and Wednesdays (Table 2). Day of revision surgery though was different in its incidence, reaching just about statistical significance with $\mathrm{P}=0.05$. Most revision procedures were performed on Fridays, with $19.4 \%$, in comparison to Mondays with only $12.6 \%$ revision procedures (Table 3 ).

\section{Discussion}

In summary, our data could not show any effect of lunar phases on the incidence of surgical complications requiring reoperations. Any influence of the occurrence of Friday $13^{\text {th }}$ could be equally ruled out.
Table 1. Lunar phase of primary operations and reoperations in patients with surgical complications. $\mathrm{P}=0.763$.

\begin{tabular}{|c|c|c|}
\hline Lunar phase & Primary operation & Reoperation \\
\hline New moon & $3.6 \%$ & $3.1 \%$ \\
\hline Waxing moon & $47.6 \%$ & $45.5 \%$ \\
\hline Full moon & $3.9 \%$ & $4.4 \%$ \\
\hline Waning moon & $44.9 \%$ & $46.1 \%$ \\
\hline
\end{tabular}

Table 2. Day of the week of primary operations with subsequent reoperation due to complications. $\mathrm{P}=0.227$.

\begin{tabular}{|c|c|}
\hline Week day & Percentage \\
\hline Monday & 16.9 \\
\hline Tuesday & 21.3 \\
\hline Wednesday & 19.7 \\
\hline Thursday & 19.2 \\
\hline Friday & 16.4 \\
\hline Saturday & 3.0 \\
\hline Sunday & 3.6 \\
\hline
\end{tabular}

Table 3. Day of reoperation due to surgical complication. $\mathrm{P}=0.05$.

\begin{tabular}{|c|c|}
\hline Week day & Percentage \\
\hline Monday & 12.6 \\
\hline Tuesday & 16.4 \\
\hline Wednesday & 15.3 \\
\hline Thursday & 16.7 \\
\hline Friday & 19.4 \\
\hline Saturday & 10.4 \\
\hline Sunday & 8.5 \\
\hline
\end{tabular}

This is supported by previous studies on the impact of lunar phases on patients presenting to the emergency department, incidence of myocardial infarction and cardiac death, on emergency operations and intraoperative blood loss and postoperative haemorrhage after thyroid surgery and tonsillectomies $[5,7,9,15]$.

Dubois, et al. (2017) investigated the 30-day mortality with 402 499 elective operations between 2002 und 2012 and could not find a significant difference between elective procedures performed on Mondays or Fridays. But it is worth mentioning that most procedures were performed on Tuesdays ( $n=95654$ vs. Friday, $n=65$ 139) [2].

Nandra, et al. analyzed the weekend effect in comparison to the 30-day mortality with 2061 patients with fractures of the proximal femur. They could not show a significant difference in the mortality for patients coming in on weekdays or weekends. There was a slightly higher mortality on weekdays than on weekends $(10,2 \%$ vs. $9,7 \%$ on weekends), and specific in respect to day of the week (12,96\% Monday vs. $8,06 \%$ Thursday) [16].

Patients with ruptured abdominal aortic aneurysms and their overall mortality rate within a ten-year span were analyzed by Kozka, et al. and whereas the mean atmospheric pressure and other weather factors, including phases of the moon, did not correlate with ruptured abdominal aortic aneurysms occurrence or its mortality, the mortality was significantly higher during national holidays and weekends in comparison to weekdays [17].

Vohra, et al. demonstrated a higher mortality within one year in patients undergoing major elective colorectal resections on Fridays in comparison to patients being operated on from Monday to Thursday. They stated though that the increased mortality might reflect patient factors rather than hospital variables alone, since patient characteristics differed between the two groups [18]. A previous study compared mortality after nonemergent major surgery performed on Friday 
versus Monday through Wednesday. Here a significantly higher 30-day mortality rate was also found for procedures taking place on Fridays, but when adjusting for patient characteristics, the odds ratio decreased, but was still highly significant [19]. This was confirmed by Aylin et al (2013), analyzing 30-day mortality after elective surgery, with a heightened risk, if surgery was performed on Friday (odds ratio 1.44) or a weekend (odds ratio 1.82) compared with Monday [20].

On the contrary Sessler, et al. investigated whether the timing of general surgery, specifically increasing time of day, increasing day of week, July/August cases versus other months and moon phase were independently related to 30-day mortality at the Cleveland Clinic between 2005 and 2010. They could not demonstrate any differences between weekday, time of day or different months concerning 30-day mortality, concluding that surgery was safe on any day and any time of the week [21].

No statistical significance could be found with patient collectives for the analysed outcomes and interrelation with moon phases or Friday $13^{\text {th }}$. Nevertheless, a firm belief in lunar influences on humans exist in up to $40 \%$ of society and appears difficult to defy [22]. Hardly any study could provide serious evidence for a lunar effect on illness. An exemption being a recent study on 6.250 consecutive stroke admissions in Canada though showed a higher incidence of intracerebral hemorrhage and transient ischemic attack during the first quarter of the lunar phase and full moon, whereas ischemic stroke was not influenced, which is difficult to explain biologically [23].

Quality of radical cystectomy with respect to progression free survival was studied in a smaller sample size of patients with bladder cancer with respect to lunar influences, as well as long-term survival and morbidity and mortality after lung surgery in cancer patients $[12,14]$. A study on lunar constellations on minor surgical procedures such as herniotomy, hemorrhoidectomy and crossectomy yielded only $3.7 \%$ complications without any major complications [24]. Neither study showed a lunar effect.

\section{Conclusions}

The present retrospective analysis on surgical complications could not show a heightened risk of complications with subsequently needed reoperations due to the primary procedure being performed on certain weekdays. The weekdays of revision surgery were of statistical significance though, with most reoperations taking place on friday. Since more than $50 \%$ of the complications occurred within four days and more than $70 \%$ within seven days postoperatively, timing of the primary operation might be worth reconsidering. This study therefore provides no reason to avoid planning of major surgery at the end of the week.

\section{Acknowledgements}

The statistical office of Dr. Johannes Gladitz, Berlin, is to be thanked for the invaluable help with the statistical analysis.

\section{Declaration of interest}

The authors declare that they have no competing interests.

\section{References}

1. Köbberling J, Wunder E (1998) Zeitfragen der Medizin. Zeitfragen der Medizin, conference proceedings pp. 35-44.

2. Dubois L, Vogt K, Vinden C et al (2017) Association between day of the week of elective surgery and postoperative mortality. CMAJ 189: E303-e9.
3. Scanlon TJ, Luben RN, Scanlon FL, Singleton N (1993) Is Friday the 13th bad for your health? BMJ 307: 1584-1586. [Crossref]

4. Abell GO, Greenspan B (1979) Human births and the phase of the moon. N Engl J Med 300: 96. [Crossref]

5. Wolbank S, Prause G, Smolle-Juettner F, Smolle J, Heidinger D, et al. (2003) The influence of lunar phenomena on the incidence of emergency cases. Resuscitation 58: 97-102. [Crossref]

6. Alves DW, Allegra JR, Cochrane DG, Cable G (2003) Effect of lunar cycle on tempora variation in cardiopulmonary arrest in seven emergency departments during 11 years. Eur J Emerg Med 10: 225-228. [Crossref]

7. Eisenburger PSW, Vergeiner G (2003) Lunar phases are not related to the occurrence of acute myocardial infarction and sudden cardiac death. Resuscitation 56: 187-189.

8. Belleville G F-BG, Dixon G (2013) Impact of seasonal and lunar cycles on psychological symptoms in the ED: an empirical investigation of widely spread beliefs. Gen Hosp Psychiatry 35: 192-194.

9. Promberger R, Ott J, Mikola B (2010) Lunar phase does not influence the incidence of postoperative haemorrhage after thyroid surgery: an analysis of 26,852 operations. European Surgery 42: 72-76.

10. Komann M, Weinmann C, Meissner W (2014) Howling at the moon? The effect of lunar phases on post-surgical pain outcome. Br J Pain 8: 72-77. [Crossref]

11. Schuld J, Slotta JE, Schuld S, Kollmar O, Schilling MK, et al. (2011) Popular belief meets surgical reality: impact of lunar phases, Friday the 13th and zodiac signs on emergency operations and intraoperative blood loss. World J Surg 35: 1945-1949. [Crossref]

12. Kuehnl A, Herzog M, Schmidt M, Hornung HM, Jauch KW, et al. (2009) The dark side of the moon: impact of moon phases on long-term survival, mortality and morbidity of surgery for lung cancer. Eur J Med Res 14: 178-181. [Crossref]

13. Peters-Engl C, Frank W, Kerschbaum F, Denison U, Medl M, et al. (2001) Lunar phases and survival of breast cancer patients--a statistical analysis of 3,757 cases. Breast Cancer Res Treat 70: 131-135. [Crossref]

14. May M, Braun KP, Helke C, Richter W, Vogler H, et al. (2007) Lunar phases and zodiac signs do not influence quality of radical cystectomy--a statistical analysis of 452 patients with invasive bladder cancer. Int Urol Nephrol 39: 1023-1030. [Crossref]

15. Kumar VV, Kumar NV, Isaacson G (2004) Superstition and post-tonsillectomy hemorrhage. Laryngoscope 114: 2031-2033. [Crossref]

16. Nandra R, Pullan J, Bishop J, Baloch K, Grover L, et al. (2017) Comparing mortality risk of patients with acute hip fractures admitted to a major trauma centre on a weekday or weekend. Sci Rep 7: 1233. [Crossref]

17. Kózka MA, Bijak P, Chwala M, Mrowiecki T, Kotynia M, et al. (2014) The impact of weather factors, moon phases, and seasons on abdominal aortic aneurysm rupture. Ann Vasc Surg 28: 542-546. [Crossref]

18. Vohra RS, Pinkney T, Evison F, Begaj I, Ray D, et al. (2015) Influence of day of surgery on mortality following elective colorectal resections. Br J Surg 102: 12721277. [Crossref]

19. Zare MM, Itani KM, Schifftner TL, Henderson WG, Khuri SF (2007) Mortality after nonemergent major surgery performed on Friday versus Monday through Wednesday. Ann Surg 246: 866-874. [Crossref]

20. Girard N (2014) Evidence appraisal of Aylin P, Alexandrescu R, Jen MH, Mayer EK, Bottle A. Day of week of procedure and 30 day mortality for elective surgery: retrospective analysis of hospital episode statistics. BMJ 99: 821-825. [Crossref]

21. Sessler DI, Kurz A, Saager L, Dalton JE (2011) Operation timing and 30-day mortality after elective general surgery. Anaesth Analg 113: 1423-1428.

22. Vance DE (1995) Belief in lunar effects on human behavior. Psychol Rep 76: 32-34 [Crossref]

23. Mao YSY, Busija L (2015) MOONSTROKE: Lunar patterns of stroke occurrence combined with circadian and seasonal rhythmicity--A hospital based study. Chronobiol Int 32: 881-888.

24. Holzheimer RG, Nitz C, Gresser U (2003) Lunar phase does not influence surgical quality. Eur J Med Res 8: 414-418. [Crossref]

Copyright: (C2017 Müller V. This is an open-access article distributed under the terms of the Creative Commons Attribution License, which permits unrestricted use, distribution, and reproduction in any medium, provided the original author and source are credited. 